\title{
Characterization and overexpression of the Aspergillus niger gene encoding the CAMP- dependent protein kinase catalytic subunit
}

\author{
Mojca Bencina, ${ }^{1,2}$ Henk Panneman, ${ }^{1}$ George J. G. Ruijter, ${ }^{1}$ Matic Legiša ${ }^{2}$ \\ and Jaap Visser ${ }^{1}$
}

Author for correspondence: Jaap Visser. Tel: +31 317484439 . Fax: + 31317484011

e-mail: office@algemeen.mgim.wau.nl

1 Wageningen Agricultural University, Section Molecular Genetics of Industrial Microorganisms, Dreijenlaan 2, $6703 \mathrm{HA}$

Wageningen, The

Netherlands

2 National Institute of Chemistry, Hajdrihova 19, SLO-61115 Ljubljana, Slovenia
The gene pkaC encoding the catalytic subunit of CAMP-dependent protein kinase has been isolated from the industrially important filamentous fungus Aspergillus niger. A probe for screening A. niger phage libraries was generated by a polymerase chain reaction using degenerate primers. CDNA and genomic DNA clones were isolated and sequenced. An open reading frame of $1440 \mathrm{bp}$, interrupted by three short introns, encodes a polypeptide of $\mathbf{4 8 0}$ amino acids with a calculated molecular mass of $53813 \mathrm{Da}$. The CAMP-dependent protein kinase catalytic subunit (PKA-C) from A. niger has a 126 amino acid extension at the N-terminus compared to the PKA-C of higher eukaryotes that - except for the first 15 amino acids, which are homologous to the Magnaporthe grisea PKA-C - shows no significant similarity to the $\mathbf{N}$-terminal extension of PKA-C of other lower eukaryotes. The catalytic core of PKA-C of A. niger shows extensive homology with the PKA-C isolated from all other eukaryotes. Lowstringency hybridization did not reveal any other pkaC homologue in $A$. niger. The cloned pkaC was used for transformation of $A$. niger, leading to increased levels of pkaC mRNA and PKA-C activity. Transformants overexpressing pkaC were phenotypically different with respect to growth, showing a more compact colony morphology, accompanied by a more dense sporulation, especially on media containing trehalose and glycerol. A number of transformants also showed a strongly reduced or complete absence of sporulation. This phenotype was quickly lost upon propagation of the strains.

Keywords: cAMP-dependent protein kinase catalytic subunit, Aspergillus niger, PKA-C overexpression, defective sporulation

\section{INTRODUCTION}

cAMP-dependent protein kinase (PKA) plays a crucial role in the regulation of metabolic pathways by means of enzyme phosphorylation (Walsh \& van Patten, 1994). Furthermore, it modulates the function of nuclear factors that bind to DNA sequences present in the promoter regions of cAMP-inducible genes (Lalli \& Sassone-Corsi, 1994). In fungi, PKA appears to be involved in the control of the activity of a large number

\footnotetext{
Abbreviations: PKA, CAMP-dependent protein kinase; PKA-C and PKA-R, catalytic and regulatory subunit of PKA, respectively; RT-PCR, reverse transcription PCR.

The EMBL accession number for the nucleotide sequence reported in this paper is $\mathrm{X} 94399$.
}

of enzymes. PKA has a role in aerobic germination of the dimorphic fungus Mucor rouxii (Rossi \& Moreno, 1994) and in differentiation processes of the slime mould Dictyostelium discoideum (Mann \& Firtel, 1993). The most detailed investigation on the function of PKA in signal transduction has been carried out with Saccharomyces cerevisiae (Thevelein, 1994). In S. cerevisiae, PKA activity is essential for growth, cell cycle progression, sporulation and sensitivity to various forms of stress (Toda et al., 1987b). PKA mediates the expression of cytosolic catalase T (CTT1) (Marchler et al., 1993), an HSP70 gene (SSA3) (Boorstein \& Craig, 1990) and trehalose phosphate phosphatase (TPS2) (Gounalaki \& Thireos, 1994).

In the filamentous fungus Aspergillus niger, 6phosphofructo-1-kinase seems to be phosphorylated by 
PKA (Legiša \& Bencina, 1994), possibly influencing the rate of glycolysis. PKA might also be involved in morphology changes in $A$. niger during an early stage of citric acid fermentation, because the morphology changes coincide with changes in cAMP concentration (Legiša \& Grapulin-Gradišnik, 1995).

According to its mechanism of activation PKA is one of the simplest members of a large protein kinase family. In most cases the inactive form of PKA is a tetrameric protein composed of two regulatory and two catalytic subunits. Upon binding of cAMP, inactive PKA dissociates into two active catalytic subunits and a dimer of regulatory subunits. Several isoforms of PKA subunits, encoded by distinct genes, have been identified in higher eukaryotes (Døskeland et al., 1993). In mammals three different genes encoding distinct catalytic subunits $(\mathrm{C} \alpha, \mathrm{C} \beta, \mathrm{C} \gamma)$ have been found, whereas two types of regulatory subunits have been isolated and four different genes encoding PKC-R have now been identified (Taylor et al., 1992). It seems that the presence of only one type of regulatory subunit is the rule in lower eukaryotes (Mutzel et al., 1987; Toda et al., 1987b). Genes encoding the catalytic subunit of PKA have been isolated from a number of fungi including Magnaporthe grisea (Mitchell \& Dean, 1995), S. cerevisiae (Toda et al., 1987a), Blastocladiella emersonii (de Oliveira et al., 1994), Schizosaccharomyces pombe (Maeda et al., 1994) and D. discoideum (Mann \& Firtel, 1991). In S. cerevisiae three isoenzymes of the catalytic subunit have been found (Toda et al., 1987a). PKA was purified from the fungi Neurospora crassa (Powers \& Pall, 1980) and Mucor rouxii (Pastori et al., 1985), and more recently also from A. niger (Legiša \& Bencina, 1994). PKA from $D$. discoideum differs in structure from the others: it is a dimeric protein composed of one catalytic and one regulatory subunit (Mutzel et al., 1987).

In order to analyse the A. niger PKA in more detail and to study its role in the regulation of glycolysis and morphology, cDNA and genomic DNA clones of the catalytic subunit of PKA have been isolated and sequenced and $A$. niger strains overexpressing the cloned gene constructed.

\section{METHODS}

Strains and plasmids. The $A$. niger strains used were: $A$. niger wild-type N400 (CBS 120.49) and A. niger NW219 [cspA1 nicA1 leuA1 pyrA6], which was used for transformation. Escherichia coli DH5 $\alpha\left[\mathrm{F}^{-} /\right.$endA1 hsdR17 $\left(\mathrm{r}_{\mathrm{k}}^{-} \mathrm{m}_{\mathrm{k}}^{+}\right)$supE44 thi-1 recA1 gyrA $\left(\mathrm{Nal}^{r}\right)$ relA1 $\Delta$ (laclZYA-argF)U169 deoR ( $\phi 80 \mathrm{~d}$ lac $\Delta$ (lacZ) M15)] (New England Biolabs) was used for propagation of plasmid DNA and E. coli LE392 [ $\Delta$ (laclZY $) 6$ galK2 galT22 metB1 trpR55 $\lambda^{-}$] (Promega) and BB4 [LE392, $\Delta(\operatorname{argF-lacZ}) U 169 \quad \mathrm{~F}^{\prime} \quad$ lacl $^{\mathrm{a}} \mathrm{Z} \Delta \mathrm{M} 15$ proAB $\left.\mathrm{Tn} 10 \quad\left(\mathrm{Tet}^{\mathrm{r}}\right)\right]$ (Stratagene) were used for phage amplification and purification. Phage R408 (Stratagene) was used as a helper phage for phagemid excision. Plasmid vector pGEM-T (Promega) was used for cloning PCR fragments, pBluescript KS (Stratagene) was used for subcloning and plasmid pGW635 containing the $A$. niger orotidine-5-phosphate decarboxylase (pyrA) gene (Goosen et al., 1987) was used as selection plasmid in transformation of $A$. niger.
Culture media and growth conditions. For the preparation of conidiospores A. niger strains were grown at $30^{\circ} \mathrm{C}$ for $3-4 \mathrm{~d}$ on complete medium, originally described for Aspergillus nidulans (Pontecorvo et al., 1953), using $2 \%(\mathrm{w} / \mathrm{v}$ ) glucose as a carbon source unless stated otherwise, with appropriate supplements and solidified with $1.5 \%(\mathrm{w} / \mathrm{v})$ agar. In liquid cultures the mycelium was grown by inoculating $10^{6}$ conidiospores $\mathrm{ml}^{-1}$ in medium containing, per litre: $6 \mathrm{~g} \mathrm{NaNO}_{3}, 1.5 \mathrm{~g}$ $\mathrm{KH}_{2} \mathrm{PO}_{4}, 0.5 \mathrm{~g} \mathrm{KCl}, 0.5 \mathrm{~g} \mathrm{MgSO}_{4} .7 \mathrm{H}_{2} \mathrm{O}, \mathrm{pH} 6.0,0.2 \mathrm{ml}$ trace metal solution (Visniac \& Santer, 1957), 1 g yeast extract and $1 \mathrm{~g}$ Casamino acids, using $2 \%(\mathrm{w} / \mathrm{v})$ glucose as a carbon source and appropriate supplements, which are, for $A$. niger NW219, $1 \mathrm{mg}$ nicotinamide, $200 \mathrm{mg}$ leucine and $1200 \mathrm{mg}$ uridine. The mycelium was grown at $30^{\circ} \mathrm{C}$ in a rotary shaker (New Brunswick) at 250 r.p.m.

Chemicals and enzymes. Restriction enzymes, DNA polymerase I Klenow fragment, M-MuLV reverse transcriptase, bacteriophage T4 DNA ligase and T4 DNA polymerase were obtained from Life Technologies; bacteriophage T7 DNA polymerase and Taq DNA polymerase from Pharmacia; $[\alpha-$ $\left.{ }^{32} \mathrm{P}\right] \mathrm{dATP}$ and $\left[{ }^{35} \mathrm{~S}\right] \mathrm{dATP} \gamma \mathrm{S}$, from Amersham; dNTPs from Boehringer. All other chemicals used were of analytical grade.

DNA manipulation. A. niger chromosomal DNA was isolated as described by de Graaff et al. (1988). Propagation of plasmid DNA, isolation of plasmid DNA, Southern blot analysis and other DNA manipulations were essentially done as described by Sambrook et al. (1989). [ $\alpha{ }^{32}$ P]dATP-labelled probes were synthesized using random hexamer primers (Sambrook et al., 1989). Sequencing was done using the dideoxy chain-termination procedure (Sanger et al., 1977) with the T7 DNA polymerase sequencing kit (Pharmacia). For sequence determination, DNA restriction fragments were subcloned into pBluescript vectors and sequenced with the M13 universal, reverse and gene-specific oligonucleotide primers. Sequence analysis was done using the PC/GENE (Intelligenetics) program and the GCG suite. Digital images of autoradiograms were acquired using a CCD camera. The composite image of the Northern blot analysis was created using the CorelDraw 4.0 software package.

RNA manipulation. For isolation of $A$. niger total RNA, TRIZOL (Life Technologies) was used. Poly(A) ${ }^{+}$mRNA was isolated by oligo(dT) column chromatography (Sambrook et al., 1989). For Northern blot analysis, $15 \mu \mathrm{g}$ RNA aliquots were separated on formaldehyde agarose gels, blotted to nylon membranes (Hybond-N, Amersham) and hybridized with $[\alpha-$ $\left.{ }^{32} \mathrm{P}\right] \mathrm{dATP}$-labelled probes. Hybridization was performed at $42{ }^{\circ} \mathrm{C}$ in $0.9 \mathrm{M} \mathrm{NaCl}, 0.09 \mathrm{M}$ disodium citrate, $0.5 \%$ Ficoll $400,0.5 \%$ polyvinylpyrrolidone, $0.5 \%$ BSA fraction $\mathrm{V}, 100 \mu \mathrm{g}$ denatured herring sperm DNA ml ${ }^{-1}, 0.5 \%$ SDS and $50 \%$ formamide. The blots were washed under conditions of high stringency at $65^{\circ} \mathrm{C}$ with $0.3 \mathrm{M} \mathrm{NaCl}, 0.03 \mathrm{M}$ disodium citrate, $0.5 \%$ SDS, $\mathrm{pH} 7.0$ (homologous conditions) or under conditions of low stringency at $56^{\circ} \mathrm{C}$ with $0.6 \mathrm{M} \mathrm{NaCl}, 0.06 \mathrm{M}$ disodium citrate, $0.5 \%$ SDS, $\mathrm{pH} 7 \cdot 0$ (heterologous conditions).

Transformation of $\boldsymbol{A}$. niger. Mycelium was prepared by growing $A$. niger NW219 in liquid culture on complete medium with appropriate supplements for 16-18 h. The preparation of protoplasts and subsequent transformation of A. niger NW219 were performed essentially as described by Kusters-van Someren et al. (1991). The A. niger pyrA gene was used as a selection marker. For transformation, $1 \mu \mathrm{g}$ pGW635 DNA and $20 \mu \mathrm{g}$ of the co-transforming plasmid pPKAC1 were added to $2 \times 10^{7}$ protoplasts.

Isolation of the genomic and cDNA clones. The A. niger $p k a C$ 
and the corresponding cDNA clone were isolated by homologous hybridization, using a PCR-generated fragment (see below) as a probe, from an $A$. niger N400 genomic library in the $\lambda$ replacement vector EMBL4 (Promega) (Harmsen et al., 1990 ) and a cDNA library from $A$. niger N400 glucoseoxidase-induced mycelium in $\lambda$ ZAP II (Stratagene) (Witteveen et al., 1993), respectively. Plasmids containing the cloned cDNAs were obtained from the $\lambda$ ZAP II phages by in vivo excision according to the manufacturer's instructions.

Polymerase chain reaction (PCR). Phage DNA (200 ng), isolated from the amplified glucose-oxidase-induced CDNA library (see above) was used as a template in the PCR. The $100 \mu \mathrm{l}$ reaction volume contained $50 \mathrm{mM} \mathrm{KCl}, 1.5 \mathrm{mM} \mathrm{MgCl}_{2}$, $10 \mathrm{mM}$ Tris/HCl pH 9.0, $200 \mu \mathrm{M}$ dNTPs, $2.5 \mathrm{U}$ Taq DNA polymerase and degenerate primers PA (0.264 nmol; 5'YANAARCARRTNGARCA-3') and PB (0.132 nmol; $5^{\prime}$ CCACCARTCNACNGMYTT-3'). Conditions for PCR were: $3 \mathrm{~min}$ at $95^{\circ} \mathrm{C}$; three cycles of $95^{\circ} \mathrm{C} / 1 \mathrm{~min}$, $35^{\circ} \mathrm{C} / 1.5 \mathrm{~min}$ and $72^{\circ} \mathrm{C} / 1 \mathrm{~min} ; 30$ cycles of $95^{\circ} \mathrm{C}, 43^{\circ} \mathrm{C}$ and $72^{\circ} \mathrm{C}$, each of $1 \mathrm{~min}$. The final elongation step was done at $72{ }^{\circ} \mathrm{C} / 5 \mathrm{~min}$.

Reverse transcription PCR (RT-PCR). Poly (A) ${ }^{+}$mRNA (100 ng) was denatured for $10 \mathrm{~min}$ at $68^{\circ} \mathrm{C}$ in the presence of $1 \mu \mathrm{M}$ primer P9 (5'-CAGAGGTATGATGGGCA-3') (Fig. 2). Subsequently the reverse transcription buffer $(50 \mathrm{mM}$ Tris $/ \mathrm{HCl}$ pH 8.3, $75 \mathrm{mM} \mathrm{KCl}, 3 \mathrm{mM} \mathrm{MgCl}, 10 \mathrm{mM}$ DTT, $500 \mathrm{mM}$ $\mathrm{dNTPs}$ ) and $200 \mathrm{U}$ M-MuLV reverse transcriptase were added and the mixture was incubated at $42^{\circ} \mathrm{C}$ for $1 \mathrm{~h}$. One-fourth of this reaction was used in a $100 \mu \mathrm{l} P C R$ reaction with $300 \mathrm{nM}$ of primers P9 and P11 (5'-GTTTAGGAGGTTTGCTG-3') (Fig. 2), $50 \mathrm{mM} \mathrm{KCl}, 1.5 \mathrm{mM} \mathrm{MgCl}, 10 \mathrm{mM}$ Tris $/ \mathrm{HCl} \mathrm{pH}$ $9.0,500 \mu \mathrm{M}$ dNTPs and $2.5 \mathrm{U}$ Taq polymerase. The empirically determined conditions were: denaturation step $95^{\circ} \mathrm{C} / 3 \mathrm{~min} ; 5$ cycles of $95^{\circ} \mathrm{C} / 10 \mathrm{~s}, 56{ }^{\circ} \mathrm{C} / 40 \mathrm{~s}, 72^{\circ} \mathrm{C} / 1 \mathrm{~min}$; 30 cycles of $95^{\circ} \mathrm{C} / 10 \mathrm{~s}, 52^{\circ} \mathrm{C} / 40 \mathrm{~s}, 72{ }^{\circ} \mathrm{C} / 1 \mathrm{~min}$; and a final elongation step at $72^{\circ} \mathrm{C}$ for $5 \mathrm{~min}$. The products were cloned and sequenced.

Enzyme assay. Mycelium grown in liquid culture for $20 \mathrm{~h}$ was harvested by filtration, washed briefly with ice-cold $0.8 \%$ $\mathrm{NaCl}$, and frozen in liquid nitrogen. The frozen mycelium $(0.5 \mathrm{~g})$ was ground and suspended in extraction buffer $(25 \mathrm{mM}$ Tris $\mathrm{pH} 7 \cdot 4,10 \mathrm{mM} \mathrm{MgCl}, 0 \cdot 15 \mathrm{M} \mathrm{NaCl}, 1 \mathrm{mM}$ DTT, $1 \mathrm{mM}$ EDTA). After $30 \mathrm{~min}$ extraction the homogenate was centrifuged at $10000 \mathrm{~g}$ for $10 \mathrm{~min}$. The clear supernatant was used for the enzyme assay. Two- to tenfold dilutions of cell extracts (the protein concentration of cell extracts was around $2 \mathrm{mg}$ $\mathrm{ml}^{-1}$ ) were used. The enzyme activity was measured by the nonradioactive Spinzyme (Pierce) method with dye-labelled Kemptide as a substrate according to the manufacturer's protocol. The incubation time of an assay was $30 \mathrm{~min}$ at $30^{\circ} \mathrm{C}$. A unit of enzyme activity is defined as the amount of enzyme required to transfer 1 pmol phosphate from ATP to substrate (Kemptide) $\mathrm{min}^{-1}$ at $30^{\circ} \mathrm{C}$. PKA-C enzyme (bovine heart, Pierce) with known activity was used as a standard.

Protein concentrations were determined by the bicinchoninic acid protein assay kit (Sigma) according to the supplier's instructions. Bovine serum albumin (fraction V) (Boehringer) was used as a standard.

Primer extension mapping. Poly $(\mathrm{A})^{+} \mathrm{mRNA}$ was isolated from mycelium grown for $20 \mathrm{~h}$. Poly $(\mathrm{A})^{+} \mathrm{mRNA}(6 \mu \mathrm{g})$ and primer P12 (5'-TTCTTCAGCAAACCTCC-3') (Fig. 2) $(5 \mu \mathrm{g})$ were used for primer extension mapping, which was performed according to Calzone et al. (1987) with minor modifications. The reaction products were analysed on a denaturing polyacrylamide gel parallel to a dideoxy sequence reaction of genomic pPKAC1 clone using primer P12.

\section{RESULTS \\ Cloning of the pkaC gene}

The primers used for preparation of a probe by PCR were based on well-conserved regions of eukaryotic PKA-C proteins. To avoid possible introns interfering with proper primer annealing, cDNA from $A$. niger N400 was chosen as a template. Under the empirically determined conditions, as described in Methods, a product of approximately $420 \mathrm{bp}$ was found (data not shown). Sequence analysis of this fragment revealed high similarity with the $p k a C$ of other organisms.

The A. niger $\mathrm{N} 400$ genomic and cDNA libraries were screened by homologous hybridization using the $420 \mathrm{bp}$ PCR product as a probe. Screening of $10^{5}$ p.f.u. of the genomic and the cDNA library resulted in 50 positive genomic clones and two positive cDNA clones. Five genomic phages and both cDNA phages were purified. The genomic phages were characterized by restriction analysis and a $5 \mathrm{kbp} E c o R I$ fragment was isolated and cloned in pBluescript, resulting in plasmid pPKAC1 (Fig. 1). The cDNA clones were found to be identical and were isolated by in vivo excision, resulting in plasmid pPKAC2, for which a detailed restriction map is also given (Fig. 1).

Although isoforms of PKA-C exist in several organisms, low-stringency hybridization did not reveal the existence of any other $p k a C$ homologue in A. niger N400.

\section{Sequence of the pkaC gene and primary structure of its deduced protein}

The nucleotide sequence of the $3245 \mathrm{bp}$ EcoRI-XbaI fragment of pPKAC1 was determined from both strands (Fig. 2). The cDNA clone was sequenced to establish

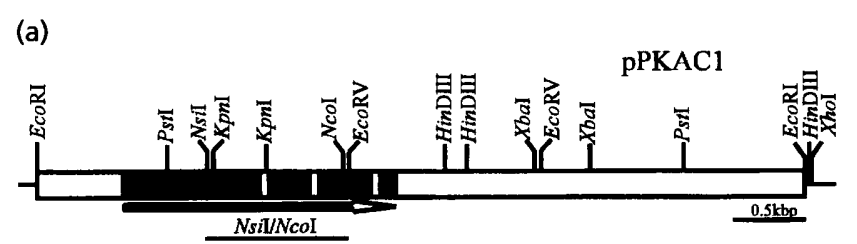

(b)

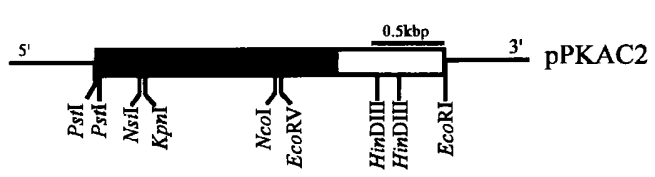

Fig. 1. (a) Restriction map of clone PPKAC1 isolated from the genomic $A$. niger N400 library. The line below the restriction map indicates the Nsil-Ncol fragment that was used as a probe for Southern and Northern hybridization analysis. (b) Restriction map of CDNA clone pPKAC2. The coding region is presented as a filled box; open boxes indicate non-coding regions and introns. The open arrow indicates the direction of transcription. 
gaattcacgccaatccaacccogctctectctcctttgetteccetttttccatttttccactccetctctccatcaaac - 625

taatcaaaataattataatgaaataggataakaattgcggtgcttgtgctcgtagtgttttcagctagttggtttagtagtagtagt - 535 $\mathrm{C}_{4} \mathrm{~T} \quad \mathrm{C}_{4} \mathrm{~T}$

agtggtggtgctggtcacagcaagcatctctttccetcccetctcatctcttctcctctctcctctctttctccccctcaccatcagcat - 445

catcagcatcatcatcgatcctcccgcacaccagccatactctcaccacccaccecceggtccaagctatcatcccacgagattcecgca - 355 $\mathrm{C}_{4} \mathrm{~T}$

ctcccccgcgttacatattctccettcttatccggacatcetcacggtcgeccgtetg ccaattgagtttccgttgaccgccgttcggg - 265

accagtgttctgttctgtttgggggctccgetgtatcegcgeccgaacccgtcccaagagaaaaagctcgccgetttccetctccatatt - 175 $\mathrm{C}_{4} \mathrm{~T}$

$\mathrm{C}_{4} \mathrm{~T}$

attcttactgtgttgettcctttcccacccccctctctgagagcatctcttaaagaggggtcgcgttgatctgctatcgcacgcatcct - 85

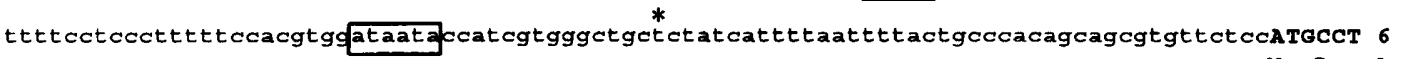

$\mathrm{P} 12$

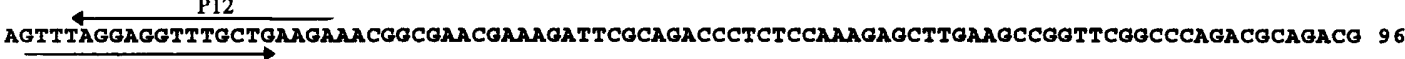

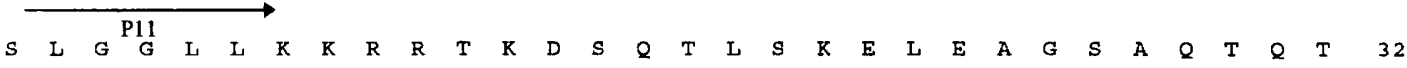
TCACCAAACGCTGCCGAAGACCACCACAACCACAACCACCACCAACACCACCACCACCTCTTCCACCACCACCATCAACCCCAACCCGCC 186

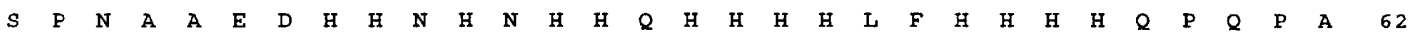
ACCAATTCTGGCTCTGCAGCAAACACCCCCCCTCAGCCTCAAGATTCCGTGCCTCAACAGTCCAATCGGTCTTCGGGAGCAGAAAAATCC 276 $\begin{array}{lllllllllllllllllllllllllllllllllllll} & T & N & S & G & S & A & A & N & T & P & P & Q & P & Q & D & S & V & P & Q & Q & S & N & R & S & S & G & A & E & K & S & 92\end{array}$ TCCGACGGTCAGGTAGCCTCCATGCAATCCGCTGTGACGCAAGCCTCGCCOTCTGCCCATCATACCTCTGGCCTCCCGCAGCCCAATGCC 366 $\begin{array}{lllllllllllllllllllllllllllllllllll}S & D & G & Q & V & A & S & M & Q & S & A & V & T & Q & A & S & P & S & A & H & H & T & S & G & \text { L } & P & Q & P & N & A & 122\end{array}$

AATGCGGCTAGTATACAGAATATAATTACCCCTCCCAGCAAGGCGCCATGCATTCGOCTTCCAGTGGTCATACGCAATCTCACCATGCC 456 $\begin{array}{lllllllllllllllllllllllllllllllllllllllll}N & A & A & S & I & Q & N & I & I & N & P & S & Q & Q & G & A & M & H & S & A & S & S & G & H & T & Q & S & H & H & A & 152\end{array}$ GGTCGCAGTGATGCCCGCACCACCAAAgGGAATACTCCTTGGATGACTTCAGCCTTCAGCGCACCCTGGGTACCGGTAGCTTCGGTCGC 546 $\begin{array}{llllllllllllllllllllllllllllllllllllllllll}G & R & S & D & A & R & T & T & K & G & K & Y & S & L & D & D & F & S & I & Q & R & T & L & G & T & G & S & F & G & R & 182\end{array}$ GTGCACTTGGTGCAGTCGAAGCACAACCATCGCTTCTACGCTGTCAAGGTGCTGAAGAAGGCGCAAGTGGTCAAGATGAAACACATTGAG 636

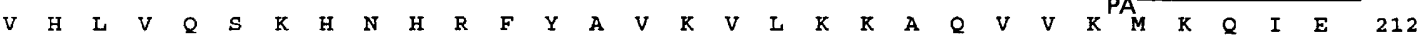
CACACCAACGATGAGCGCCOATGCTGAATCGCGTCAGACATCCATTCCTAATCACATTATGgGgTACATGGCAGGATTCCCGGACTTG 726 \begin{tabular}{llllllllllllllllllllllllllllllllllllll}
\hline$H$ & $T$ & $N$ & $D$ & $E$ & $R$ & $R$ & $M$ & $L$ & $N$ & $R$ & $V$ & $R$ & $H$ & $P$ & $F$ & $L$ & $I$ & $T$ & $I$ & $W$ & $G$ & $T$ & $W$ & $Q$ & $D$ & $S$ & $R$ & $N$ & $L$ & 242
\end{tabular} TACATGGTCATGGACTTCGTAGAgGGTGTGAACTCTCAGTCTCOTCCGCAAGTCACAggtgggttattctgacttggCcCgCCCgaCC 816

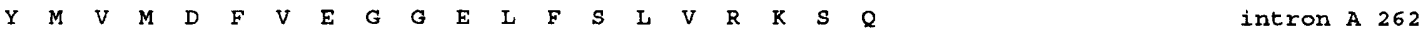
aacgtaagetgatgtctggtacctctttcatgtagCGGTTCCCCAACCCCGTCGCCAAGTTCTATGCGGCGGAAGTCACTCTTGCCCT 906 $\begin{array}{llllllllllllllllllll}R & F & P & N & P & V & A & K & F & Y & A & A & E & V & T & L & A & L & 280\end{array}$ TGAGTACTTGCACACGCAGAACATCATCTACCGGGATCTCAAGCCCGAGAACTTGCTGCTAGACCOCCACGGCCATCTGAAGATCACCGA 996 $\begin{array}{llllllllllllllllllllllllllllllllllllll}E & Y & L & H & T & Q & N & I & I & Y & R & D & L & K & P & E & N & L & L & L & D & R & H & G & H & L & K & I & T & D & 310\end{array}$ TTTCGGTTTTGCCAAGGAGTGCCTGACATCACATGGACCCTTTGTGOTACTCCCGATTATCTCGCCCCGOAGGTGGTTCCTCTAAGGG 1086 $\begin{array}{lllllllllllllllllllllllllllllllllll}F & G & F & A & K & E & V & P & D & I & T & W & T & L & C & G & T & P & D & Y & I & A & P & E & V & V & S & S & K & G & 34 & 0\end{array}$ TTATAACAAGTCGGTTGACTGgtaagggttgccattattgatgttcatgtccctttggcgcaggttactaatgatgcgaaagGTGGTCTC 1176 $\begin{array}{lllllllllll} & N & K & S & V & D & W & \text { intron } B & & & \end{array}$ TGGGGATTTGATCTTCGAGATGCTGTGTGGTTTCACGCCTTTCTGGGACAGTGOCTCCCCAGTCAAGATCTACGAGAACATCCTGCGTG 1266

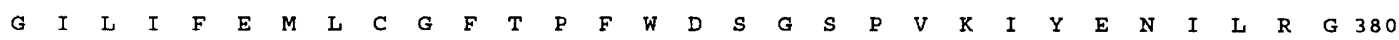
GCAGGGTAAAATACCCOCCCTACCTGCACCCGGATGCTGTTGATCTGCTGTCGCAACTGATCACGGCTGATCTGACCAAACGCCTTGGAA 1356

$\begin{array}{llllllllllllllllllllllllllllllllll}R & V & K & Y & P & P & Y & \text { L } & \text { H } & \text { P } & \text { D } & \text { A } & \text { V } & \text { D } & \text { L } & \text { L } & S & \text { Q } & \text { L } & \text { I } & \text { T } & \text { A } & \text { D } & \text { L } & \text { T } & \text { K } & \text { R } & \text { L } & \text { G } & \text { N } & 410\end{array}$ ACCTCCATGGCGGTCGGATGATGTCAAGATCATCCTTGGTTTGCCGAGGTCACCTGGGACCGTTTGGCCCGCAAGGATATCGACGCTC 1446 $\begin{array}{llllllllllllllllllllllllllllllllllllll}L & H & G & G & S & D & D & V & K & N & H & P & W & F & A & E & V & T & W & D & R & L & A & R & K & D & I & D & A & P & 440\end{array}$ CTTACGTGCCTCCCATCCGTGGTGGCCAAGGAGATGCGAGTCAGTATGACCGCTATCCGGAAGAAACTGAACAGTATGGCATGGCTGGTG 1536 $\begin{array}{llllllllllllllllllllllllllllllllllllll}Y & V & P & P & I & R & G & G & Q & G & D & A & S & Q & Y & D & R & Y & P & E & E & T & E & Q & Y & G & M & A & G & E & 470\end{array}$ AAGACCCgtatgtgctatcttcccatttcctaataacgcgtggtgggtcacattactgaogctgcttgoagacacoocCATTTGTrCCC 1626 $\begin{array}{llllllllll}D & P & \text { intron C } & H & H & F & P & 48\end{array}$ AGACTTCTAGtgtgtgctacgagttatgatggaatgattgtctcgctaccgagatggcatcgtgtcatccgatgatattgcgagccetgt 1716 D F 480 aagacaggactatctcgctaatccttaccctctgtgctaccaaaggtagcaccacacccatcattcgttgagttccccttgacgtcggtt 1806 tgtcttcgttatttgatcgctggccgacttgcttttggctacctttgacgtagagcatatatctaagagctctgtcattctcagcgtat 1896 gccttcaccatcttcaagtatacgctatggtettatctatetgctttccggtatceggactgttggtggtctgcatataagcttacc 1986 cttatatgagctctggggagatctgatgagtggatgattteceggtgatctttatctaggtgggcattgtctatatttcctcgcgttat 2076 gccaggcaggagggtgtttgcggtggtgtttgtgccggaagcttcgggggtttctcgtgattatgccgaccgttgactggtgaatggtca 2166 ccagcggcacccgtttcttettcaatgtttcctgcttattctatagtcatattgtgcaaatactggggagctactctgggtcattcttg 2256 atgtcatctttccgtttatgccttccctgtccctgtggcggcagttgtataatgtacatattcgatttggccattgcaataaaagtagt 2346 cttggataagtggacgctggtcccciactgtatcataagcatagcetgccattcaaggctcttgtctttcaaaagccaccggctgccc 2436 gaaccaaaaccgtccgtccgtaatatacacaaagatcatcacacaccaatggccactgcctcatatcacaccaaggtataccggtcaaaa 2526 acacctctaga 2537

Fig. 2. For legend see facing page. 
intron borders. Since the isolated cDNA clone pPKAC2 was shorter than the coding region of $p k a C$, RT-PCR was used to determine the presence of possible introns in the region upstream of the cloned cDNA. It was found that the part of $p k a C$ lacking in pPKAC2 was not interrupted by introns.

The structural region is interrupted by three short introns, $67 \mathrm{bp}, 61 \mathrm{bp}$ and $65 \mathrm{bp}$ in length (Fig. 2). The positions of all three introns found in $p k a C$ of $A$. niger are conserved between $A$. niger and Magnaporthe grisea (Mitchell \& Dean, 1995), suggesting that the $p k a C$ genes of these fungi are closely related. The presence of introns has also been reported for $p k a C$ genes of Caenorhabditis elegans (Gross et al., 1990) and Blastocladiella emersonii (de Oliveira et al., 1994). The borders of intron B (5' GTAAGG and 3' $\underline{A} A G)$ do not fit to the consensus sequence as proposed by Unkles (1992), whereas they do in introns $\mathrm{A}$ and $\mathrm{C}$. Similar aberrant $3^{\prime}$ and $5^{\prime}$ splice sites were found in the A. niger var. awamori glaA gene and in the pelA gene of A. niger (Unkles, 1992).

Primer extension analysis (data not shown) revealed that the major transcription start point is located $41 \mathrm{nt}$ upstream from the deduced AUG start codon. A putative TATA box (ATAATA) is found $20 \mathrm{nt}$ upstream from the transcription start point $(-61 \mathrm{nt}$ from the start codon) and a putative CCAAT box is found upstream at position -292 . The promoter region has long stretches of CT-rich regions, five CCCCT elements $\left(\mathrm{C}_{4} \mathrm{~T}\right.$ or inverse complement) and an AT-rich region between positions -580 and -630 (Fig. 2).

Downstream of the proposed stop codon, the mRNA still contains $727 \mathrm{nt}$ of non-coding area as indicated by the cDNA sequence. A putative polyadenylation signal AATAAA is found $702 \mathrm{bp}$ downstream from the stop codon (Fig. 2).

The deduced length of the mRNA is $2204 \mathrm{nt}$, containing a $1440 \mathrm{nt}$ open reading frame encoding a 480 aa protein (Fig. 2). The calculated molecular mass of the protein is $53813 \mathrm{Da}$ and the theoretical isoelectric point is $7 \cdot 8$.

Statistical analysis of codon usage showed that a wide range of codons is used for $p k a C$. A relatively high frequency of codons using $A$ in the third position was found. The most striking difference from most fungal genes was found in the case of Lys and Gln, for which $36 \%$ and $41 \%$ of the codons were AAA and CAA, respectively. These codons are hardly ever used in the currently known $A$. niger genes.

The 480 aa $A$. niger PKA-C protein has a 126 aa Nterminal extension compared to PKA-C of higher eukaryotes. Analysis of the gene using the GCG program Testcode indicated that the larger part of this area is possibly coding (data not shown). A strong argument in favour of the proposed AUG start codon is the high similarity (over $70 \%$ ) of the first 15 aa of the A. niger and Magnaporthe grisea proteins. The A. niger PKA-C exhibits a sequence identity of over $50 \%$ with the PKA$\mathrm{C}$ of higher eukaryotes and over $60 \%$ with the PKA-C of lower eukaryotes when only the catalytic core is considered (Fig. 3). The N-terminal extension of PKA-C of $A$. niger shows no significant homology with the $\mathrm{N}$ terminal extension of PKA-C of lower eukaryotes except for the extreme $\mathrm{N}$-terminal part of the ascomycete $M$. grisea PKA-C (underlined in Fig. 3).

\section{Transformation of $A$. niger with the pkaC gene}

Co-transformation of $A$. niger with pGW635 and pPKAC1 and subsequent expression analysis was performed to prove the functionality of the cloned gene. From 80 transformants, initially selected for uridine prototrophy, over $50 \%$ were phenotypically different from the parental strain, NW219. Some of the transformants lacked or had retarded sporulation; others had dense sporulation. Sporulation defects were accompanied by slow growth. During preservation the transformants showing no or retarded sporulation turned out to be very unstable and reverted to the phenotype of the parental strain (Fig. 4). We were not able to maintain these phenotypes. Four apparently stable transformants were chosen for further analysis. Southern analysis revealed single-copy ectopic integrations for transformants $w 1,3$ and 13 and multicopy ectopic integration for transformant 53. In contrast to strain 53, no obvious rearrangements of integrated $p k a C$ copies were present in transformants $w 1,3$ and 13 (data not shown).

\section{Expression of pkaC}

Northern blot analysis of total RNA of the transformant and wild-type strains using the NsiI-Ncol fragment of $p k a C$ as a probe (Fig. 1) showed two- to fourfold increased levels of mRNA in transformed strains w1, 3 and 13. Strain 53 showed a truncated mRNA and an increased level of mRNA of the size of the wild-type (Fig. 5). The results of the Northern analysis were also confirmed by dot-blot analysis (data not shown). The level of overexpression is slightly higher, as might be expected from the single copy integrations. This discrepancy might be caused by the genomic environment of the integration site, or a specific regulatory mechanism such as titration of a specific repressor protein.

In order to prove that the transcribed $p k a C$ was also translated, PKA-C activities were measured in cell extracts of $A$. niger NW219 and transformants. Elevated levels of PKA-C activity were found in the transformed

Fig. 2. Nucleic acid sequence and deduced amino acid sequence of the $A$. niger pkaC gene. The coding part of the gene is typed in upper-case. The ultimate $5^{\prime}$ and $3^{\prime}$ bases of the CDNA insert from PPKAC2 are marked with filled triangles. The positions of primers PA and PB used for generating a probe for screening the libraries and the primers used in RT-PCR and primer extension experiments are indicated by arrows. Intron B splits primer PB. The putative TATA motif and CCAAT sequence are boxed. The transcription start point is marked by an asterisk. Putative $C_{4} T^{T}$ elements are underlined. The ATrich region is indicated by a dotted line. The putative polyadenylation signal is underlined. 
$M g$

$S p$

An

$M g$

$S p$

$\mathrm{Be}$

An qpatnsgsaantppqpqdsvpqqsnrssgaekssdgqvasmqsavtgaspsahhtsglpqpnanaasiqn

$M g$ vqqqnsqpsanfqpqsqsqsqsqsqfplppshgngdqsqqqnfqvqqqiqsqqdamdiqpsqvqdqshsq

$S p$ kskkpdslvststsgcasahsvgyqnidnlipsplpesasrsssqsshqrhsrdgrgelgsehgerrsam

Be lmektkkvvgssdkdapapaspsspstaagagsasstasstttaaasgnlsipsplvagsttsssishaq

Sc

Bo

An iinpsqqgamhsassghtgshhagrsdarttkgkyslddFslqrTLGTGSFGRVhLVqskhnhrfYAvKv

$M g$ qaqpqhqpqhhvqhhvnhahqgsqdqqtrvtkgkysltdFeilrTLGTGSFGRVhLVgsrhngr fYAvKv

Sp dglrdrhirkvrvsqlldlqrrrirpadhttkdrygiqdFnflqTLGTGSFGRVhLVqSnhnrlYYAiKv

$B e$ kmataahtnsdyspspaatpsapldavaerrrrkttladLelrqTLGTGSFGRVhLVrlrstgkyYAmKv

Sc kkgseqesvkeflasagiclvkkpmlqyrdtsgkyslsdFqilrTLGTGSFGRVhLIrsnhngrfYAlKt

Bo aaakkgsegesvkeflakakedflkkwenpagntahldqFerikTLGTGSFGRVmLVkhmetgnhYAmKi

An LkKaqvVkmKQIEHTndErrmLnrVrhPFlitIwgtWqDsrnl YMVMDFveGGELFslvRksqkFpnpvA

Mg LkKaqVVkmkQVEHTndErkmLgeVknPF litLwgt FqDCrnlYMVMDVVeGGELFs l lRksgRFpnpvA

Sp LeKkkIVdmKQIEHTCdEryiLsrVqhPFitiLwgtFqDaknlFMMDFaeGGELFs liRrigRFsephA

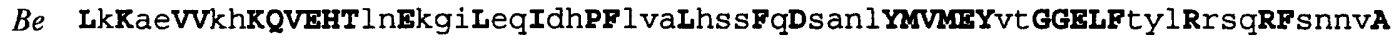

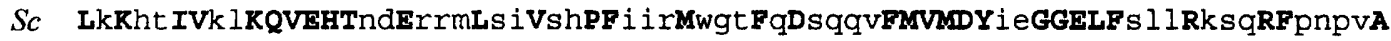

Bo

An KFYAAEVtLaLEYLHTQniIYRDLKPENILIDThGhlkItDFGFAKeVp.dITWTLCGTPDYIAPEVVss

Mg kFYAAeVtLaLEYLHakni i YRDLKPEN1LlDrhGhlkItDFGFAKrVp. dkTWTLCGTPDYlAPEVVsn

$S p$ kFYAAeViLaLDYLHhnq i VYRDLKPENILIDrfGhlkIVDFGFAKrVstdiTWTLCGTPDYIAPEIIqS

$B e$ kFYAAeVvLaFEYLHSkdi i YRDLKPENILlDaqGhvkItDFGFAKhVp. diTWTLCGTPDYIAPEIIqS

Sc kFYAAeVCLaLEYLHSkdit YRDLKPEN iLlDknGhikItDFGFAKYVp. dVTYTLCGTPDY iAPEVVst

Bo rFYAAqIVL TFEYLHS Idl I YRDLKPENIL IDqqGY I qVTDFGFAKrVK. grTWTLCGTPEYIAPEIIIS

An kgYnksvDWWsLGILIFEMICGF tPFWdsgspvkiYEnIlrgrvkYPpylhpdavDLLsqLitaDltkRL

Mg kgYnksvDWWsLGILIYEMI CGYpPFWds gspmk i YEnIlkgkvrYPay inpdaqDLLqrL itaDl tkRL

$S p$ kpYnkaaDWWSLGILIFEMI aGYPPFY. senpmk l YEnIlegkvnYPsy f spasiDLLShLl grD itCRY

$B e$ rgYgravDWYaLGVLIFEMlaGYpPFYd edhvrmYEkIlqgkvkWPshfdpaakDLLkrLlttDltkRY

Sc kpYnksvDWWSFGVLIYEMlaGYtPFYnsn.tmkt YEnIlnaelkFPpf fhpdaqDLLkkLitrDlseRL

Bo kgYnkavDWWaLGvLIYEMaaGYpPFFa. dqpiqi YEkIvsgkvrPPshfs SdlkDLLrnLlqvDltkRF

An GNLhgGsdDVknHpWFaevtWdrlarkdIdaPYvPpirgGqGDaSqYDrYpEetegYgmagedphghlfpdF 480

Mg GNLYgGsqDVrnHpWFaevtWdrlarkdIdaPYt PpvkaGaGDaSqPDrYpEeterygqtghdeygnlfpgF 534

$S p$

Be

Sc

Bo GNLkdGsmDI imHpWFrdisWdkiltrkIevPYvPpiqaGmGDsSqFDaYaDvatdygtsedpefts ifkdF 512 GNLkgGskDIkmHkWFagldWtk lfnkqIppPYtPpnr. GdGDtSnFDaYpFetepygkvqpdpyaqlfkdF 425 GNLqnGseDVknHpWFneviWekl laryIet PYePpiqqGqGDtSqFDrYpEeefnygiqgedpymdlmke 398 GNLkdGvnDIknHkWFattdWiaiyqrkVeaPFiPkfk.GpGDtSnFDdYeEeeirvsi..nekcgkefser 350

Fig. 3. Alignment of the PKA-C protein sequences of A. niger (An), Magnaporthe grisea (Mg; Mitchell \& Dean, 1995), Schizosaccharomyces pombe (Sp; Maeda et al., 1994), Blastocladiella emersonii (Be; de Oliveira et al., 1994), Saccharomyces cerevisiae type C (SC; Toda et al., 1987a) and bovine type $\alpha$ (Bo; Wiemann et al., 1992). Conserved amino acids are printed in upper-case. The positions of the $A$. niger introns are indicated by arrows. Asterisks indicate the conserved autophosphorylation sites. The amino acids in the $\mathrm{N}$-terminal region that are conserved between $\mathrm{A}$. niger and M. grisea are underlined.

strains w1, 3 and 13, with the highest activity measured in strain 13 . Strain 53 had the same enzyme activity as the wild-type $A$. niger strain NW219 (Table 1). If the truncated mRNA observed for strain 53 results in a protein, this might interfere with the PKA-C assay. The low expression measured for strain 53 might also have 


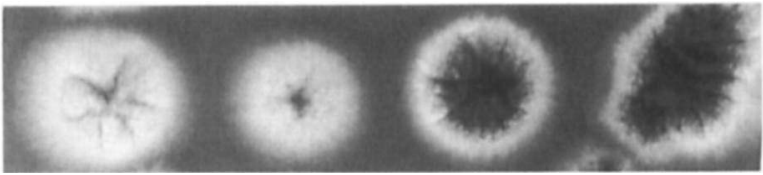

Fig. 4. Instability of an originally non-sporulating transformed strain upon propagation. The original transformant strain was propagated on minimal medium containing $1 \%$ glucose as a carbon source. Four successive generations are shown.

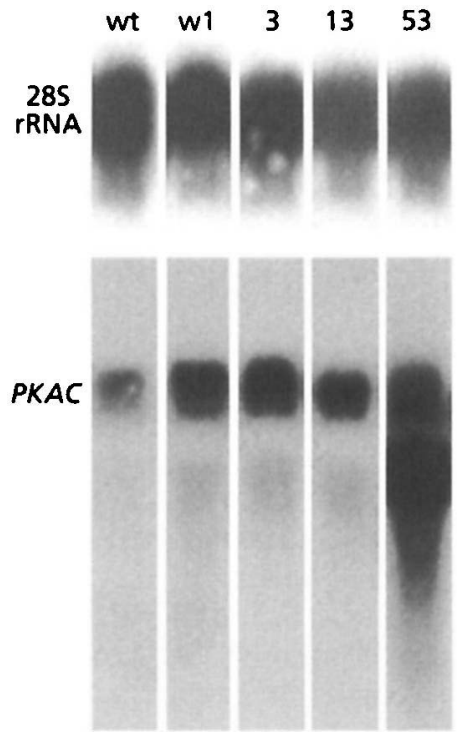

Fig. 5. Northern analysis of total RNA of the pkaC transformants and the wild-type (wt) of A. niger. RNA was quantified using a $28 \mathrm{~S}$ rRNA probe of Agaricus bisporus (EMBL accession X91812).

Table 1. PKA-C activities in extracts from $A$. niger NW219 and from transformed strains

Values are the means of two independent experiments, \pm the range.

\begin{tabular}{|lcc|}
\hline Strain & $\begin{array}{c}\text { Specific activity } \\
{\left[\mathbf{U}(\mathbf{m g} \text { protein })^{-1}\right]}\end{array}$ & $\begin{array}{c}\text { Activity ratio } \\
\text { transformant: NW219 }\end{array}$ \\
\hline NW219 & $65 \pm 3$ & 1 \\
w1 & $120 \pm 8$ & $1 \cdot 8$ \\
3 & $142 \pm 38$ & $2 \cdot 2$ \\
13 & $244 \pm 51$ & $3 \cdot 8$ \\
53 & $64 \pm 4$ & 1 \\
\hline
\end{tabular}

been caused by the observed instability of the non- or low-sporulating strains.

\section{Phenotypic characterization of pkaC-overexpressing strains}

The conidiospores of a few selected transformants were plated on minimal medium agar plates with different

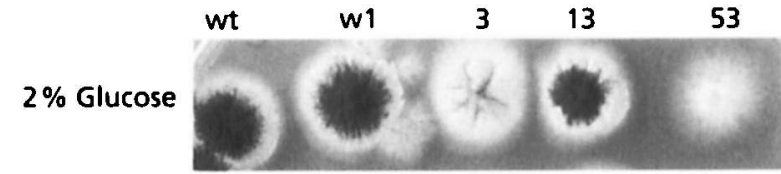

$3 \%$ Trehalose

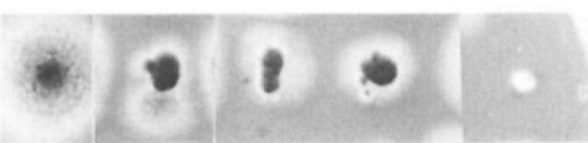

$10 \%$ Glycerol

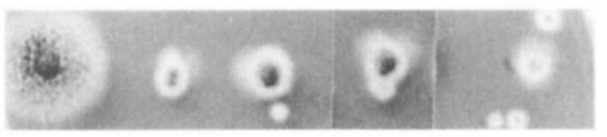

$2 \%$ Acetate

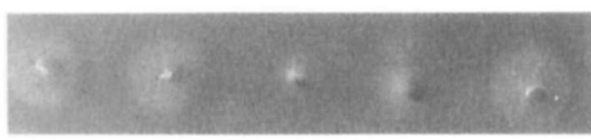

$2 \%$ Glucose 5 mM CAMP

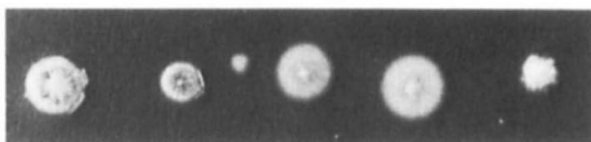

Fig. 6. Phenotypic characterization of PKA-C-overexpressing strains. Strains were grown for $5 \mathrm{~d}$ at $30^{\circ} \mathrm{C}$ on minimal medium, containing the carbon sources indicated.

carbon sources. All transformants selected grew more slowly than the control, A. niger NW219 transformed to uridine prototrophy. Particularly on media containing $3.4 \%(\mathrm{w} / \mathrm{v})$ trehalose, $10 \%(\mathrm{v} / \mathrm{v})$ glycerol (Fig. 6$), 1.5 \%$ $(\mathrm{w} / \mathrm{v})$ xylose, and $1 \%(\mathrm{v} / \mathrm{v})$ glycerol (data not shown) as a sole carbon source, slower growth and a more dense sporulation was observed for all transformants, except for transformant 53, which showed no or almost no sporulation on any of the media tested. This is likely to be caused by the expression of a truncated PKA-C, possibly by the formation of a cAMP-insensitive complex with PKA-R or disturbance of the normal PKA$\mathrm{C} / \mathrm{PKA}-\mathrm{R}$ stoichiometry. The more dense sporulation may be either a direct effect of $p k a C$ overexpression, or an indirect effect, caused by the slower growth of the transformants on these substrates. Growth of transformants on $2 \%$ acetate was very slow, and sporulation was less dense or completely absent on this medium. On $2 \%$ glucose in the presence of $5 \mathrm{mM}$ cAMP, slow growth and almost no or no (strain 53) sporulation was observed for all strains.

\section{DISCUSSION}

\section{Sequence analysis}

The A. niger $p k a C$ gene encodes a polypeptide of 480 amino acids. The calculated molecular mass is 53813, which corresponds well with the molecular mass determined experimentally by SDS-PAGE $(53 \mathrm{kDa})$ (Legiša \& Bencina, 1994). Southern blot analysis indicated that the A. niger PKA-C is the product of a unique gene similar to the situation in Aplysia californica 
(Beushausen et al., 1988), Caenorhabditis elegans (Gross et al., 1990), Schizosaccharomyes pombe (Maeda et al., 1994) and Blastocladiella emersonii (de Oliveira et al., 1994).

Except for the 126 aa N-terminal extension the homology between A. niger PKA-C and PKA-C from other organisms is very high. Some parts of the protein are completely invariant, such as the glycine-rich loop (175LGTGSFGRV), Lys-198 and Glu-217 associated with ATP binding, and the putative active site (288IIYRDLKPENLLL) typical for Ser/Thr protein kinases. Two autophosphorylation sites, Thr-323 and Ser-415, are conserved amongst $M$. grisea, B. emersonii, the yeasts Sacch. cerevisiae and Schiz. pombe, and the A. niger PKA-C, whereas they do not contain the autophosphorylation site (Ser-338 in bovine PKA-C), which is conserved in higher eukaryotes (Fig. 3, Taylor et al., 1992). The catalytic subunit of the A. niger PKA is rather large compared to the PKA-C of higher eukaryotes due to its $\mathrm{N}$-terminal extension. The $\mathrm{N}$-terminus contains a relatively high amount of polar and charged residues and a relatively high amount of rare codons like AAA and CAA (Fig. 3). Whether the N-terminus might play a role in cellular localization, subunit interaction or a translational regulatory mechanism is unknown. No Nterminal extensions have been found in organisms containing more than one $p k a C$ gene. Based on the consensus for strong AUG initiation codons, as defined by Arst \& Sheerins (1996), the context of the first inframe initiation codon allows leaky scanning, possibly resulting in three different proteins, one starting at Met1 , one starting at Met-100 and one starting at Met-139 (Fig. 2). Differential transcription, splicing or posttranslational modifications of the unique $p k a C$ gene or its transcript might also result in isoenzymes. Transformation of gene fusions of an inducible promoter and the $A$. niger $p k a C$ at Met- 100 and Met-139 resulted in strains which showed almost no or no growth on solid media containing an inducing carbon source ( $\mathrm{M}$. Bencina, unpublished results). These results indicate that the truncated proteins are still active or still capable of binding PKA-R.

Characterization of the $A$. niger $p k a C$ promoter region revealed that a putative TATA-box and CAAT-box are present in the promoter. These elements are fairly conserved among fungi both with respect to composition and in their distance to the translation start point, although some fungal genes do not contain recognizable TATA-boxes at all (Unkles, 1992). The AT-rich region present in fungal promoters might cause unwinding and prevent nucleosome formation, making the gene more accessible to the transcriptional machinery and allowing constitutive expression (Struhl, 1985).

The importance of $\mathrm{C}_{4} \mathrm{~T}$ motifs for $p k a C$ expression regulation is unclear. In Sacch. cerevisiae, $\mathrm{C}_{4} \mathrm{~T}$ boxes were found in the promoter of the stress-response gene DDR2 (Kobayashi \& McEntee, 1993) and of the CTT1 gene, encoding cytosolic catalase $\mathrm{T}$ (Marchler et al., 1993). The $\mathrm{C}_{4} \mathrm{~T}$ elements of the CTT1 gene appear to be responsible for a four- to tenfold increase in transcription upon stress. The expression of $A$. niger $p k a C$ also increased upon osmotic shock and temperature stress (data not shown). However, whether the $\mathrm{C}_{4} \mathrm{~T}$ elements play any role in the stress response of this promoter remains to be established.

The long distance between the stop codon and the proposed polyadenylation signal $(702 \mathrm{bp}$ ) is rather unusual for A. niger. Also, a rather low codon bias is found. Highly expressed genes tend to have a preferred subset of sense codons with a low percentage of $A$ at the third position (Unkles, 1992). The Lys codon AAA, which does not appear at all in most of the published $A$. niger genes, appears nine times in PKA-C, suggesting that this might influence $p k a C$ expression levels. Our data indicate that expression of $p k a C$ appears to be fairly constant but can be elevated by certain stress conditions.

\section{Phenotypic features}

Co-transformants were initially selected on the basis of morphological differences. Similar to the situation in Sacch. cerevisiae, A. niger multicopy transformants grew more slowly than the parental strain. The growth tests indicated that even moderate overproduction of $p k a C$ affected the growth and sporulation characteristics of $A$. niger transformants. Growth on medium containing $5 \mathrm{mM}$ cAMP almost eliminates the phenotypic difference between wild-type and transformant strains that is observed on all other media tested. The overexpression of $p k a C$ is thus likely to be responsible for the observed effects. A Sacch. cerevisiae strain in which the BCY1 gene, encoding PKA-R, was disrupted, shows uncontrolled $p k a C$ activity. This strain is unable to grow on acetate, glycerol and pyruvate, but does grow on glucose. Diploid strains homozygous for the $B C Y 1$ disruption were also unable to sporulate. Even though PKA-R is not essential for growth of Sacch. cerevisiae, uncontrolled PKA-C activity does interfere with spore germination (Toda et al., 1987b). A Sacch. cerevisiae (tpk1 tpk2 TPK3 BCY1) strain containing TPK3 on a high-copy-number plasmid under the control of the GAL1 promoter even failed to grow in the presence of galactose (Mazon et al., 1993). Measurements of PKA-C and PKA-R in Mucor rouxii clearly showed that before germination started PKA-R was present in excess relative to PKA-C. Upon germination, PKA-C slowly increased (Rossi \& Moreno, 1994). In Dictyostelium discoideum, unrestrained activity of PKA-C leads to uncontrolled spore formation even under conditions where the wild-type does not sporulate. The same conditions also prematurely trigger terminal cell differentiation (Simoni et al., 1992). Our results indicate that, as in Sacch. cerevisiae, $M$. rouxii and $D$. discoideum, the PKA-C of $A$. niger also influences growth and development. Some $A$. niger transformants obtained developed only a few conidia or did not sporulate at all (data not shown). Upon propagation, these phenotypes were rapidly lost, presumably due to a 
reduction of the $p k a C$ copy number or specific suppressor mutations. The overexpression of $p k a C$ in $A$. niger did not severely affect viability but resulted in unstable transformants which were hard to maintain. The effect of disruption of the gene is currently unknown; however in Magnaporthe grisea no apparent effects on the vegetative growth rate or conidiation were found in vitro (Mitchell \& Dean, 1995).

In order to be able to overexpress the PKA-C of A. niger for further in vitro protein phosphorylation studies we have adopted two strategies: expression of $p k a C$ under control of an inducible promoter, and cloning and coexpression of the gene encoding the regulatory subunit.

\section{ACKNOWLEDGEMENTS}

M. Bencina was the recipient of a grant from the Slovenian government and was additionally funded by Wageningen Agricultural University.

\section{REFERENCES}

Arst, H. N., Jr \& Sheerin, A. (1996). Translational initiation competence, 'leaky scanning' and translational reinitiation in areA of Aspergillus nidulans. Mol Microbiol 19, 1019-1024.

Beushausen, S., Bergold, P., Sturner, S., Elste, A., Roytenberg, V., Schwartz, J. H. \& Bayley, H. (1988). Two catalytic subunits of cAMP-dependent protein kinase generated by alternative splicing are expressed in Aplysia neurons. Neuron 1, 853-864.

Boorstein, W. R. \& Craig, E. A. (1990). Regulation of a yeast HSP70 gene by a cAMP responsive transcriptional control element. EMBO J 9, 2543-2553.

Calzone, F. J., Britten, R. J. \& Davison, E. H. (1987). Mapping of gene transcription by nuclease protection assays and cDNA primer extension. Methods Enzymol 152, 611-632.

Døskeland, S. O., Maronde, E. \& Gjersten, B. T. (1993). The genetic subtypes of cAMP-dependent protein kinasefunctionally different or redundant? Biochim Biophys Acta 1178, 249-258.

Goosen, T., Bloemheuvel, G., Gysler, C., de Bie, D. A., van den Broek, H. W. J. \& Swart, K. (1987). Transformation of Aspergillus niger using the homologous orotidine- 5 '-phosphate-decarboxylase gene. Curr Genet 11, 499-503.

Gounalaki, N. \& Thireos, G. (1994). Yap1p, a yeast transcriptional activator that mediates multidrug resistance, regulates the metabolic stress response. EMBO J 13, 4036-4041.

de Graaff, L., van den Broeck, H. \& Visser, J. (1988). Isolation and expression of the Aspergillus nidulans pyruvate kinase gene. Curr Genet 13, 315-321.

Gross, R. E., Bagchi, S., Lu, X. \& Rubin, C. S. (1990). Cloning and characterisation and expression of the gene for the catalytic subunit of the cAMP-dependent protein kinase in Caenorhabditis elegans. J Biol Chem 265, 6896-6907.

Harmsen, J. A. M., Kusters-van Someren, M. A. \& Visser, J. (1990). Cloning and expression of a second Aspergillus niger pectin lyase gene (pelA): indications of a pectin lyase gene family in Aspergillus niger. Curr Genet 18, 161-166.

Kobayashi, N. \& McEntee, K. (1993). Identification of cis and trans components of a novel heat shock stress regulatory pathway in Saccharomyces cerevisiae. Mol Cell Biol 13, 248-256.

Kusters-van Someren, M. A., Harmsen, J. A. M., Kester, H. C. M. \& Visser, J. (1991). Structure of the Aspergillus niger pelA gene and its expression in Aspergillus niger and Aspergillus nidulans. Curr Genet 20, 293-299.

Lalli, E. \& Sassone-Corsi, P. (1994). Signal transduction and gene regulation: the nuclear response to cAMP. J Biol Chem 269, 17359-17362.

Legiła, M. \& Bencina, M. (1994). Evidence for the activation of 6phosphofructo-1-kinase by cAMP-dependent protein kinase in Aspergillus niger. FEMS Microbiol Lett 118, 327-334.

Legiక̌a, M. \& Grapulin-Gradišnik, M. (1995). Sudden substrate dilution induces a higher rate of citric acid production by Aspergillus niger. Appl Environ Microbiol 61, 2732-2737.

Maeda, T., Watanabe, Y., Kunitomo, H. \& Yamamoto, M. (1994). Cloning of the pka1 gene encoding the catalytic subunit of the cAMP-dependent protein kinase in Schizosaccharomyces pombe. $J$ Biol Chem 269, 9632-9637.

Mann, S. K. O. \& Firtel, R. A. (1991). A developmentally regulated putative serine/threonine protein kinase is essential for development in Dictyostelium. Mech Dev 35, 89-101.

Mann, S. K. O. \& Firtel, R. A. (1993). cAMP-dependent protein kinase differentially regulates prestalk and prespore differentiation during Dictyostelium development. Development 119, 135-146.

Marchler, G., Schuller, C., Adam, G. \& Ruis, H. (1993). A Saccharomyces cerevisiae UAS element controlled by protein kinase $\mathrm{A}$ activates transcription in response to a variety of stress conditions. EMBO J 12, 1997-2003.

Mazon, M. J., Behrens, M. M., Morgado, E. \& Portillo, F. (1993). Low activity of the yeast cAMP-dependent protein kinase catalytic subunit $\mathrm{Tpk} 3$ is due to the poor expression of the TPK3 gene. Eur J Biochem 213, 501-506.

Mitchell, T. K. \& Dean, R. A. (1995). The cAMP-dependent protein kinase catalytic subunit is required for appressorium formation and pathogenesis by the rice blast pathogen Magnaporthe grisea. Plant Cell 7, 1869-1878.

Mutzel, R., Lacombe, M.-L., Simon, M.-N., de Gunzburg, J. \& Veron, M. (1987). Cloning and $\mathrm{CDNA}$ sequence of the regulatory subunit of cAMP-dependent protein kinase from Dictyostelium discoideum. Proc Natl Acad Sci USA 84, 6-10.

de Oliveira, J.C. F., Borges, A.C. C., Marques, M. V. \& Gomes, S. L. (1994). Cloning and characterisation of the gene for the catalytic subunit of cAMP-dependent protein kinase in the aquatic fungus Blastocladiella emersonii. Eur $J$ Biochem 219, $555-562$

Pastori, R., Moreno, S. \& Passeron, S. (1985). Polymeric structure of the cyclic AMP-dependent protein kinase from the dimorphic fungus Mucor rouxii and purification of its catalytic subunit. Mol Cell Biochem 69, 55-66.

Pontecorvo, G., Roper, J. A., Hemmons, L. J., MacDonald, K. D. \& Bufton, A. W. J. (1953). The genetics of Aspergillus nidulans. Adv Genet 5, 141-238.

Powers, P. A. \& Pall, M. L. (1980). Cyclic AMP-dependent protein kinase of Neurospora crassa. Biochem Biophys Res Commun 95, 701-706.

Rossi, S. \& Moreno, S. (1994). Regulation of protein kinase A subunits during germination of Mucor rouxii sporangiospores. Eur J Biochem 222, 501-506.

Sambrook, J., Fritsch, E. F. \& Maniatis, T. (1989). Molecular 
Cloning: a Laboratory Manual, 2nd edn. Cold Spring Harbor, NY : Cold Spring Harbor Laboratory.

Sanger, F., Nicklen, S. \& Coulson, A. R. (1977). DNA sequencing with chain-terminating inhibitors. Proc Natl Acad Sci USA 74, 5463-5467.

Simoni, M. N., Pelegrini, O., Veron, M. \& Kay, R. R. (1992). Mutation of protein kinase A causes heterochronic development of Dictyostelium. Nature 356, 171-172.

Struhl, K. (1985). Naturally occurring poly (dA-dT) sequences are upstream promoter elements for constitutive transcription in yeast. Proc Natl Acad Sci USA 82, 8419-8423.

Taylor, S. S., Knighton, D. R., Zheng, J., Eyck, L. F. T. \& Sowadski, J. M. (1992). Structural framework for the protein kinase family. Annu Rev Cell Biol 8, 429-462.

Thevelein, J. M. (1994). Signal transduction in yeast. Yeast 10, 1753-1790.

Toda, T., Cameron, S., Sass, P., Zoller, M. \& Wigler, M. (1987a). Three different genes in $S$. cerevisiae encode the catalytic subunit of the cAMP-dependent protein kinase. Cell 50, 277-287.

Toda, T., Cameron, S., Sass, P., Zoller, M., Scott, J. D., McMullen, B., Hurwitz, M., Krebs, E. G. \& Wigler, M. (1987b). Cloning and characterisation of $\mathrm{BCY} 1$, a locus encoding a regulatory subunit of the cyclic AMP-dependent protein kinase in Saccharomyces cerevisiae. Mol Cell Biol 7, 1371-1377.

Unkles, S. E. (1992). Gene organisation in industrial filamentous fungi. In Applied Molecular Genetics of Filamentous Fungi, pp. 28-53. Edited by J. R. Kinghorn \& G. Turner. London: Blackie. Visniac, W. \& Santer, M. (1957). The thiobacilli. Bacteriol Rev 21, 195-213.

Walsh, D. A. \& van Patten, S. M. (1994). Multiple pathway signal transduction by the cAMP-dependent protein kinase. FASEB (Fed Am Soc Exp Biol) J 8, 1227-1236.

Wiemann, S., Kinzel, V. \& Pyerin, W. (1992). Cloning of the C $\alpha$ catalytic subunit of the bovine cAMP-dependent protein kinase. Biochim Biophys Acta 1171, 93-96.

Witteveen, C. B. F., van de Vondervoort, P. J. I., van den Broeck, H. C., van Engelenburg, F. A. C., de Graaff, L. H., Hillebrand, M. H. B. C., Schaap, P. J. \& Visser, J. (1993). Induction of glucose oxidase, catalase and lactonase in Aspergillus niger. Curr Genet 24, 408-416.

Received 31 July 1996; revised 8 November 1996; accepted 21 November 1996. 